\title{
Editorial
}

\section{Workshop on Industrial Safety and Health (WISH 2014)}

The first and inaugural "Workshop on Industrial Safety and Health (WISH 2014)" was held in Tokyo on 2nd October, 2014. This workshop is to be held every two years and aims to discuss a variety of issues on occupational safety and health between the National Institute of Occupational Safety and Health, Japan (JNIOSH) and the universities and research institutes having concluded Memorandum of Understanding (MOU) on research cooperation with JNIOSH. This time, under the main theme "How should we deal with the globalization of occupational safety and health?", two keynote speakers and nine lecturers were invited from four Korean organizations, i.e. the Occupational Safety and Health Research Institute (OSHRI), Chungbuk National University, Pukyong National University, and Seoul National University of Science \& Technology, as well as JNIOSH. Listed below are the titles of the presentations and presenters:

\section{Keynote Speech}

(1) "Globalization and Localization of Occupational Safety and Health" Mr. Yoshiyuki Fukuzawa (JNIOSH)

(2) "The outlook for global unity of hazardous area in Korea"

Dr. Sang-Won Choi (OSHRI)

\section{Lecture}

(1) "Performance evaluation of portable aerosol measuring instruments used for nanomaterial aerosol measurements" Dr. Maromu Yamada (JNIOSH)

(2) "A Development and Validation of the Slip Resistance Tester" Dr. Seung-Ju Choi (OSHRI)

(3) "A Study on the Factors Influencing on Job Stress of Korean Workers" Dr. Yujeong Lee (Pukyong National University)

(4) "Global harmonization of safety regulation for the use of industrial robots - Permission of collaborative operation and the related study in JNIOSH?" Dr. Tsuyoshi Saito (JNIOSH)

(5) "Analysis of Thermal Characteristics of Electric Wiring for Load Group in Cattle Barns"

Dr. Doo Hyun Kim (Chungbuk National University)

(6) "Particle Swarm Optimization-Based Plant Layout Modelling"

Dr. Chang Jun Lee (Pukyong National University)

(7) "Actual condition survey of noise/vibration exposure in construction workers"

Takeshi Sasaki (JNIOSH)

(8) "Analysis of Labour Accidents in Tunnel Construction and Proposals for Prevention Measures"

Dr. Naotaka Kikkawa (JNIOSH),

(9) "Weighting Factor of Consciousness between the Main Contractor and Subcontractors for Establishing Effective Risk Management in the Construction Industry"

Dr. Ki Sang Son (Seoul National University of Science \& Technology)

After the last lecture, a general discussion related to the theme of this workshop was carried out. The main points of discussion were as follows:

- How can we adjust international standards or regulations with domestic laws, standards, and practices?

- It is essential that Asian countries, especially Japan, Korea and ASEAN countries, actively disseminate information worldwide in order to be involved in the process of establishing international rules, which have long been led by the Western countries.

- How can the differences in culture, social system, physique, etc. be overcome in the area of occupational safety and health?

Excellent papers presented in the workshop have been selected and published in this special issue. I am convinced that these papers give some solution or suggestions to contemporary workplace issues not only in Japan and Korea but also the world over.

Mizuki YAMAGUMA National Institute of Occupational Safety and Health, Japan 